\title{
COMPUTATIONAL STUDY ON THE THERMAL INFLUENCE OF THE COMPONENTS OF A THERMOELECTRIC ICE MAKER ON THE ICE PRODUCTION
}

\author{
A. Rodríguez, D. Astrain, A. Martínez, J.G.Vián \\ Mechanical, Energy and Materials Engineering Department \\ Public University of Navarre, 31006 Pamplona, Spain \\ Tel: +34 948 169295, Fax: +34948 169099, e-mail: \\ antonio.rodriguez@unavarra.es
}

\begin{abstract}
The main objective of this paper is to study the thermal resistances of two components of a thermoelectric ice maker installed in a no-frost refrigerator, in order to optimize the ice production. This study is conducted via a computational model developed by the Thermal and Fluids Research Group from Public University of Navarre, explained and validated in previous papers. Firstly, three dissipaters with different space between fins are simulated using Computational Fluid Dynamics Fluent to study their influence on both the ice production and the performance of the refrigerator. The computational model predicts a maximum production of $2.82 \mathrm{~kg} / \mathrm{day}$ of ice with less than $7 \mathrm{~W}$ of extra electric power consumption, though these values depend to a great extent on the cooling and freezing power of the refrigerator. Secondly, this work focuses on reducing the size of the components in order to save raw material and reduce the cost of the device. The computational model predicts that the last design produces $2.42 \mathrm{~kg} /$ day of ice, saves $65 \%$ of raw material and reduces to the half the expenses assigned to the thermoelectric modules.
\end{abstract}

Keywords: Ice production, ice maker, thermoelectrics, computational model, thermal resistance

\section{Introduction}

Nowadays, refrigeration devices provide food preservation, air conditioning and temperature management. Common refrigeration systems based on vapour compression 
or absorption technology are been complemented with new promising alternatives, such as thermoelectric devices. In fact, several thermoelectric refrigeration applications have emerged in the last few years [1]. In this research field, Thermal and Fluids research Group from Public University of Navarre has developed several applications based on thermoelectric technology, such as dehumidifiers, refrigerators with additional thermoelectric compartments, ice makers, etc [2-6].

This paper sets out to conduct a further study on the ice production of a thermoelectric ice maker installed in a no-frost refrigerator, which was presented in a previous paper [5]. Basically, this device is composed of two Marlow DT12-8L thermoelectric modules that cool down below $0{ }^{\circ} \mathrm{C}$ four aluminium cylinders attached to them, called "fingers". Then, ice cubes form around these fingers. At the other end of the thermoelectric modules, a finned dissipator transfers heat to the wind tunnel of the refrigerator. Figure 1 shows a sketch of the system.

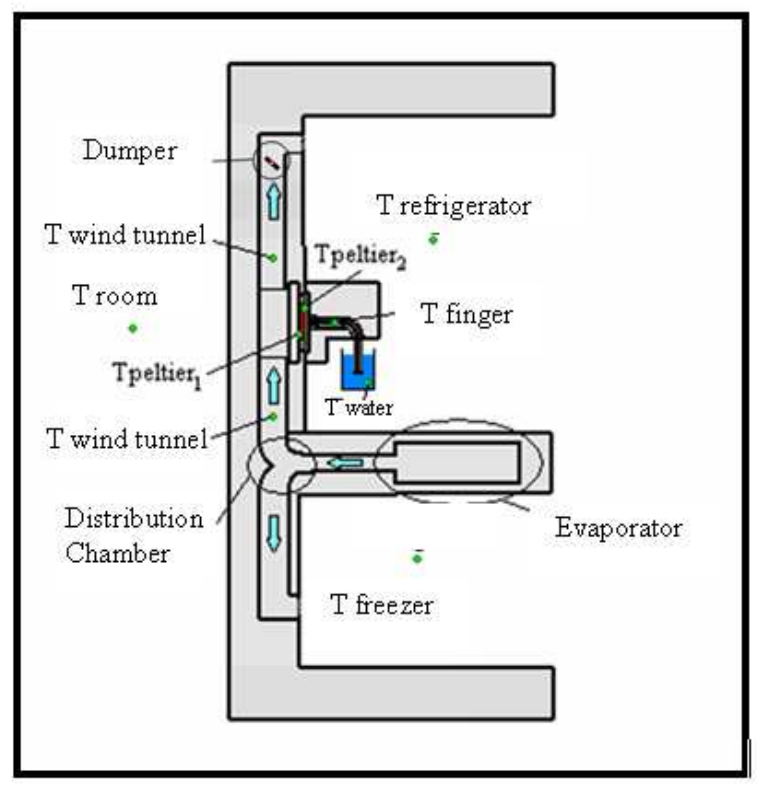

Fig. 1 Sketch of the thermoelectric ice maker and the refrigerator

This work is based on a computational model named "Simulation Model for Thermoelectric Icemakers" (MSCT) developed by our research group and presented in previous papers $[5,6]$. This model simulates both the thermal and electrical performance of the thermoelectric ice maker, the heat exchangers and the refrigerator, solving the set of equations that includes heat transfer, thermoelectric effects and phase change. MSCT represents a remarkable design tool that predicts the effects of a wide range of parameters on the ice production, electric power consumption of the ice maker, 
temperatures and heat flow rates. The input parameters can be sorted into five groups: dimensions and materials forming the thermoelectric modules; final shape and mass of the ice cubes; thermal resistances and capacities of the rest of the components; initial temperature of each component; working conditions of the refrigerator.

MSCT was used in a previous paper [6] to assess the influence of the thermoelectric modules on both the ice production and the coefficient of operation (COP) of the ice maker. This work goes further in this research and studies the influence of the dissipator and fingers. It was proved that COP of any thermoelectric refrigeration device is highly influenced by the thermal resistances of all the components, especially those installed at either side of the thermoelectric modules [7-15].

This paper presents a two-fold objective: Firstly, MSCT is used to obtain the maximum electric power supplied to the thermoelectric modules that does not affect significantly the normal performance of the refrigerator. Secondly, we study the influence of the thermal resistances of different dissipaters and fingers on the ice production, in order to save raw material and cut down on expenses.

\section{Influence of the thermal resistance of the dissipator}

Three finned dissipators with space between fins $2,3.5$ and $5.5 \mathrm{~mm}$. have been simulated using Computational Fluid dynamics (CFD) Fluent, which provides the thermal resistance of each dissipator, presented in Table 1. Moreover, as Figure 1 indicates, the dissipator is placed in the wind tunnel of the refrigerator, which affects the air flowing into the cooler compartment. In fact, the dissipator increases the pressure drop and reduces the air flow, as can be seen in Table 1, which in turn reduces the cooling power of the cooler compartment. Fluent CFD provides the percentage of air flowing into the cooler and freezer compartments for the three dissipators. Then, Table 1 indicates that the smaller the space between fins, the lower the thermal resistance but also the lower the amount of air flowing into the cooler compartment and its cooling power.

On account of the results presented in Table 1, we selected for this study the dissipator with $5.5 \mathrm{~mm}$ between fins, since the cooling power of the cooler compartment is insignificantly reduced. 


\begin{tabular}{|c|c|c|c|c|}
\hline & $\begin{array}{c}\text { No } \\
\text { dissipator }\end{array}$ & $\begin{array}{c}\text { Dissipator } \\
2 \mathrm{~mm}\end{array}$ & $\begin{array}{c}\text { Dissipator } \\
3.5 \mathrm{~mm}\end{array}$ & $\begin{array}{c}\text { Dissipator } \\
5.5 \mathrm{~mm}\end{array}$ \\
\hline $\begin{array}{l}\text { Percentage of air into the cooler compartment } \\
(\%)\end{array}$ & 28.4 & 23.8 & 26.9 & 27.9 \\
\hline $\begin{array}{l}\text { Percentage of air into the freezer compartment } \\
(\%)\end{array}$ & 71.6 & 76.2 & 73.1 & 72.1 \\
\hline $\begin{array}{l}\text { Reduction in the percentage of air into the cooler } \\
\text { compartment }(\%)\end{array}$ & - & 16.20 & 5.28 & 1.76 \\
\hline $\begin{array}{l}\text { Increase in the percentage of air into the freezer } \\
\text { compartment }(\%)\end{array}$ & - & 6.42 & 2.09 & 0.70 \\
\hline Thermal resistance of the dissipator $(\mathrm{K} / \mathrm{W})$ & - & 0.391 & 0.397 & 0.473 \\
\hline
\end{tabular}

Table 1 Influence of the space between the fins of the dissipator

In general, the performance of the refrigerator will not be affected by the thermoelectric ice maker, on condition that Eq. (1) is satisfied. In this expression, $\dot{Q}_{\text {cooler }}$ (W) stands for the cooling power of the cooler compartment, $\dot{Q}_{\text {loss }}(\mathrm{W})$ represents the heat flow rate transferred from the ambient into the cooler compartment, $\dot{m}_{\text {ice }} L_{\text {liq-ice }}(\mathrm{W})$ represents the cooling power necessary to turn liquid water into ice, and $P_{\text {therm }}(\mathrm{W})$ stands for the electric power consumed by the thermoelectric modules.

$$
\dot{Q}_{\text {cooler }} \geq \dot{Q}_{\text {loss }}+\dot{m}_{\text {ice }} L_{\text {liq-ice }}+P_{\text {therm }}
$$

The power generated by the thermoelectric ice maker $P_{T I M}(\mathrm{~W})$ is composed of the cooling power necessary to turn liquid water into ice and the electric power consumed by the thermoelectric modules, as Eq. (2) indicates.

$$
P_{T I M}=\dot{m}_{\text {ice }} L_{\text {liq-ice }}+P_{\text {therm }}
$$

From Eqs. (1) and (2), one can obtain the maximum power produced by the thermoelectric ice maker $P_{T I M \text { max }}(\mathrm{W})$ that does not affect the normal performance of the refrigerator. This variable is presented in Eq. (3).

$$
P_{T I M \max }=\dot{Q}_{\text {cooler }}-\dot{Q}_{\text {loss }}
$$

Figure 2 presents MSCT predictions of ice production versus voltage supplied to the thermoelectric modules (connected electrically in parallel), for the three dissipators. 
Furthermore, it also displays $P_{\text {therm }}$ and $P_{T I M}$ for the dissipator with $5.5 \mathrm{~mm}$ between fins. The simulation boundary conditions were:

- Thermostats of cooler and freezer compartments set at $275 \mathrm{~K}$ and $249 \mathrm{~K}$ respectively.

- Both compartments are empty.

- Initial water temperature set at $278 \mathrm{~K}$.

It can be checked that the maximum ice production is achieved when $5 \mathrm{~V}$ are supplied to the thermoelectric modules for the three dissipators. However, we must check that the normal performance of the refrigerator is not affected by the ice maker.

Focusing on the dissipator with $5.5 \mathrm{~mm}$ between fins, $P_{T I M \max }$ was experimentally calculated for these boundary conditions, being $17.4 \mathrm{~W}$. MSCT predicts that if $2.5 \mathrm{~V}$ are supplied to the modules, the ice production is $2.82 \mathrm{~kg} /$ day, $\dot{m}_{\text {ice }} L_{\text {liq-ice }}$ equals $11.1 \mathrm{~W}$, and $P_{\text {therm }}$ equals $6.25 \mathrm{~W}$; then, Eq. (2) indicates that $P_{T I M}$ equals $17.35 \mathrm{~W}$, which is similar to $P_{T I M \max }$.

Therefore, under these circumstances, the thermoelectric ice maker will not affect the normal performance of the refrigerator, on condition that the voltage supplied to the modules is lower than $2.5 \mathrm{~V}$, providing then $2.82 \mathrm{~kg}$ /day of ice with less than $7 \mathrm{~W}$ of extra electric power consumption. If we wanted to increase the ice production, a powerful cooler compartment must be installed in the refrigerator. 


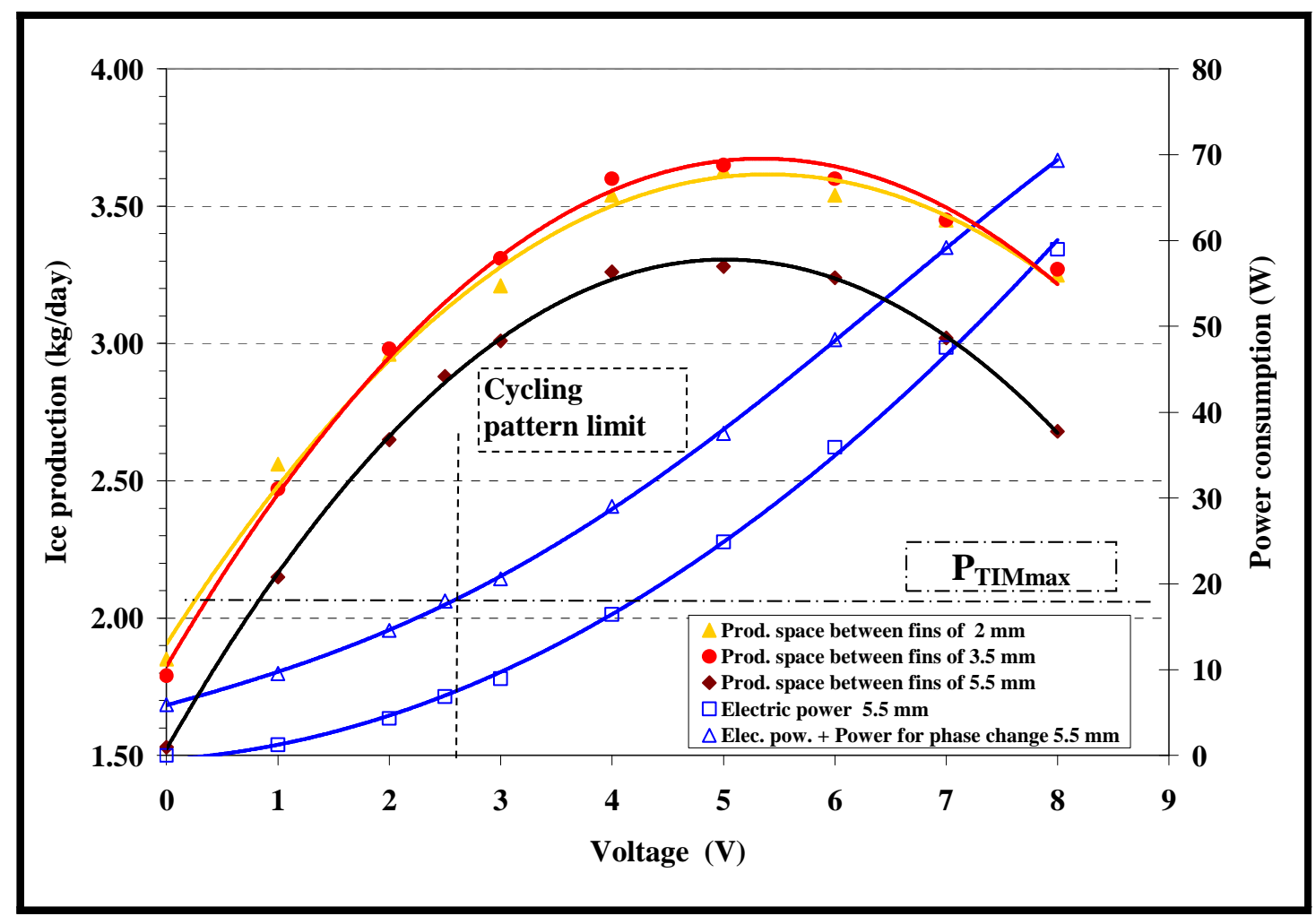

Fig. 2 Ice production and electric power consumption of the thermoelectric ice maker

\section{Influence of new designs of fingers and dissipators}

In order to save raw material and cut down on expenses, new dissipators and fingers were designed and studied with Fluent CFD.

As for the fingers, Figure 3 shows the original design used in section 2, composed of four parallel cylinders, whereas Figure 4 displays the new design, more compact and lighter than the previous one. The main advantage of this new design is the fact that the plate attached to the fingers can be reduced and adapted to the surface area of one single thermoelectric module, as explained later.

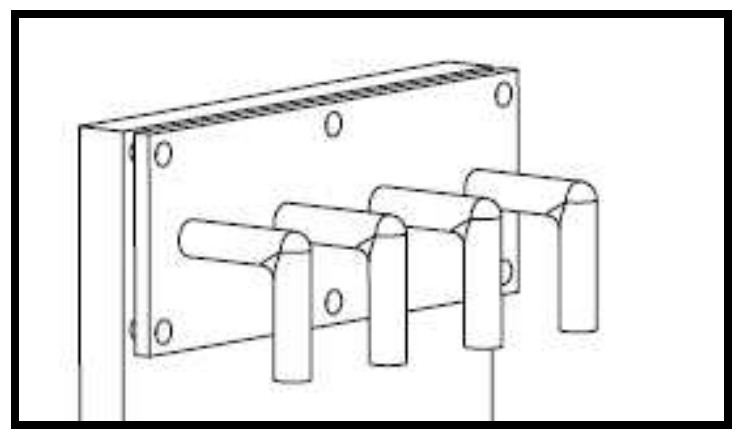

Fig. 3 Sketch of the parallel fingers 


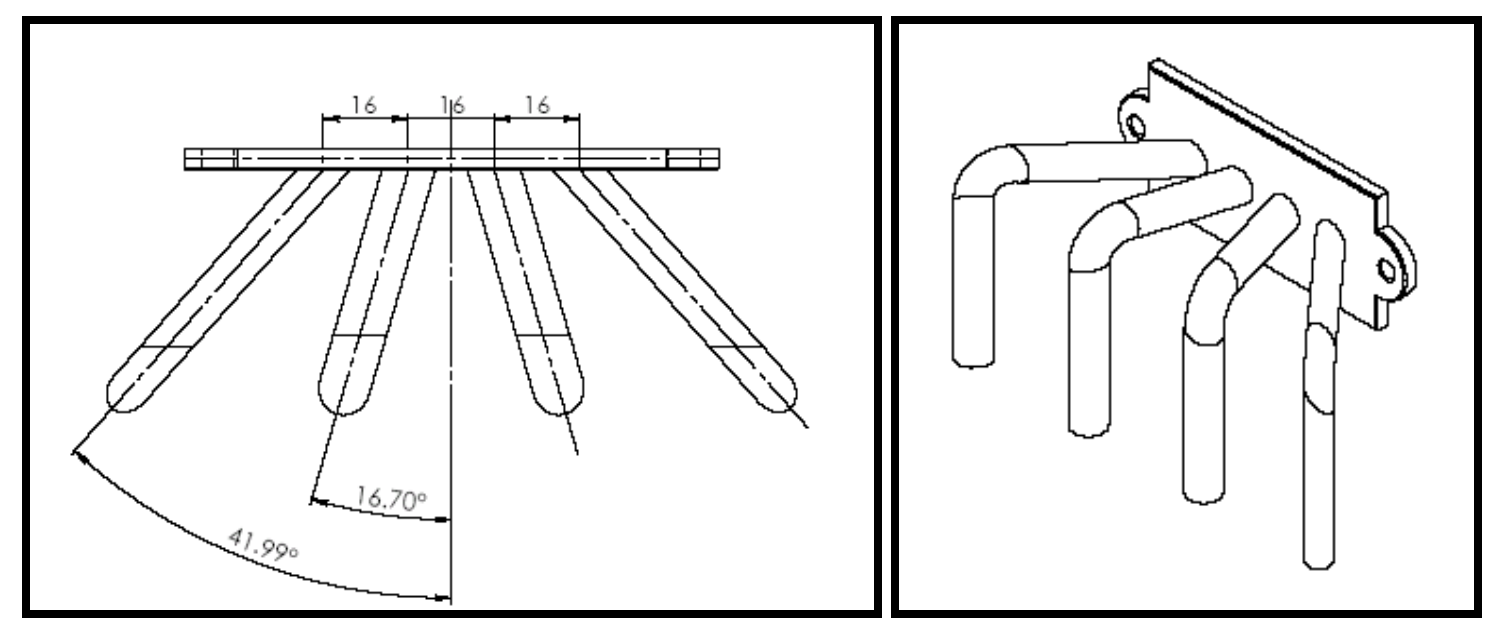

Fig. 4 Sketch of the modified fingers

Table 2 presents Fluent CFD predictions of the thermal resistances of both designs $R_{\text {fing }}(\mathrm{K} / \mathrm{W})$, which depend on the length and surface area of the fingers, and the number of thermoelectric modules installed. In fact, if we were to install one single thermoelectric module, the constriction thermal resistance (included in the thermal resistance of the fingers) would increase, since the contact area would reduce from $80 \times 40 \mathrm{~mm}^{2}$ (corresponding to two Marlow DT12-8L thermoelectric modules) to $40 \mathrm{x} 40$ $\mathrm{mm}^{2}$ (corresponding to one single Marlow DT12-8L thermoelectric module) $[16,17]$.

\begin{tabular}{|c|c|c|}
\hline Number of thermoelectric modules & Fingers & $\mathbf{R}_{\text {fing }}(\mathbf{K} / \mathbf{W})$ \\
\hline \multirow{2}{*}{2} & Parallel & 0.496 \\
\cline { 2 - 3 } & Modified & 0.570 \\
\hline \multirow{2}{*}{1} & Parallel & 0.767 \\
\cline { 2 - 3 } & Modified & 0.633 \\
\hline
\end{tabular}

Table 2 Thermal resistances of the fingers

As for the dissipator, the original design used in section 2 is composed of an aluminium plate with dimensions $155 \times 200 \times 12 \mathrm{~mm}^{3}$, and several $1.5 \mathrm{~mm}$ thick fins spaced $5.5 \mathrm{~mm}$. Now, two new designs are proposed: the first one presents a 100x200x12 $\mathrm{mm}^{3}$ base plate with $1.5 \mathrm{~mm}$ thick fins, whereas the second one is even smaller, having a 100x120x12 $\mathrm{mm}^{3}$ base plate and also $1.5 \mathrm{~mm}$ thick fins.

The comment regarding the constriction thermal resistance explained earlier also applies to this case, so that the thermal resistance of the dissipater $R_{\text {dissip }}(\mathrm{K} / \mathrm{W})$ increases if one single thermoelectric module is installed, as Table 3 points out. 


\begin{tabular}{|c|c|c|}
\hline Number of thermoelectric modules & Dissipator & $\mathbf{R}_{\text {dissip }}(\mathbf{K} / \mathbf{W})$ \\
\hline \multirow{2}{*}{2} & $155 * 200 * 12 \mathrm{~mm}^{3}$ & 0.473 \\
\cline { 2 - 3 } & $100 * 200 * 12 \mathrm{~mm}^{3}$ & 0.522 \\
\cline { 2 - 3 } & $100 * 120 * 12 \mathrm{~mm}^{3}$ & 0.647 \\
\hline 1 & $100 * 120 * 12 \mathrm{~mm}^{3}$ & 0.667 \\
\hline
\end{tabular}

Table 3 Thermal resistances of the dissipators

Finally, seven designs are proposed combining different dissipators, fingers and thermoelectric modules, which were simulated and studied with MSCT. Table 4 presents these seven combinations.

\begin{tabular}{|c|c|c|c|}
\hline Design & $\begin{array}{c}\text { Number of } \\
\text { thermoelectric modules }\end{array}$ & Fingers & Dissipator \\
\hline Original & 2 & Parallel & $155 \times 200 \times 12 \mathrm{~mm}^{3}$ \\
\hline 1 & 2 & Parallel & $100 \times 200 \times 12 \mathrm{~mm}^{3}$ \\
\hline 2 & 2 & Parallel & $100 \times 120 \times 12 \mathrm{~mm}^{3}$ \\
\hline 3 & 2 & Modified & $155 \times 200 \times 12 \mathrm{~mm}^{3}$ \\
\hline 4 & 2 & Modified & $100 \times 200 \times 12 \mathrm{~mm}^{3}$ \\
\hline 5 & 2 & Modified & $100 \times 120 \times 12 \mathrm{~mm}^{3}$ \\
\hline 6 & 1 & Parallel & $100 \times 120 \times 12 \mathrm{~mm}^{3}$ \\
\hline 7 & 1 & Modified & $100 \times 120 \times 12 \mathrm{~mm}^{3}$ \\
\hline
\end{tabular}

Table 4 Designs proposed and studied

The simulation boundary conditions are:

- Thermostats of cooler and freezer compartments set at $275 \mathrm{~K}$ and $249 \mathrm{~K}$ respectively.

- Both compartments are empty.

- Initial water temperature set at $278 \mathrm{~K}$.

- Every test lasts 35 minutes.

Figures 5, 6 and 7 presents ice production predicted by MSCT versus voltage supplied to the thermoelectric modules. 
In the first place, Figure 5 shows the influence of the dissipator on the ice production, since original design, design 1 and design 2 include parallel fingers and two thermoelectric modules, as Table 4 indicates. On one hand, for $2.5 \mathrm{~V}$ of supplied voltage, designs 1 and 2 reduce the ice production by 1.4 and $4.3 \%$ respectively with respect to that attained with the original design. On the other hand, designs 1 and 2 reduce the volume of the original dissipator by 35 and $61 \%$ respectively. In conclusion, both designs meet the main objective of saving raw material without affecting significantly the ice production.

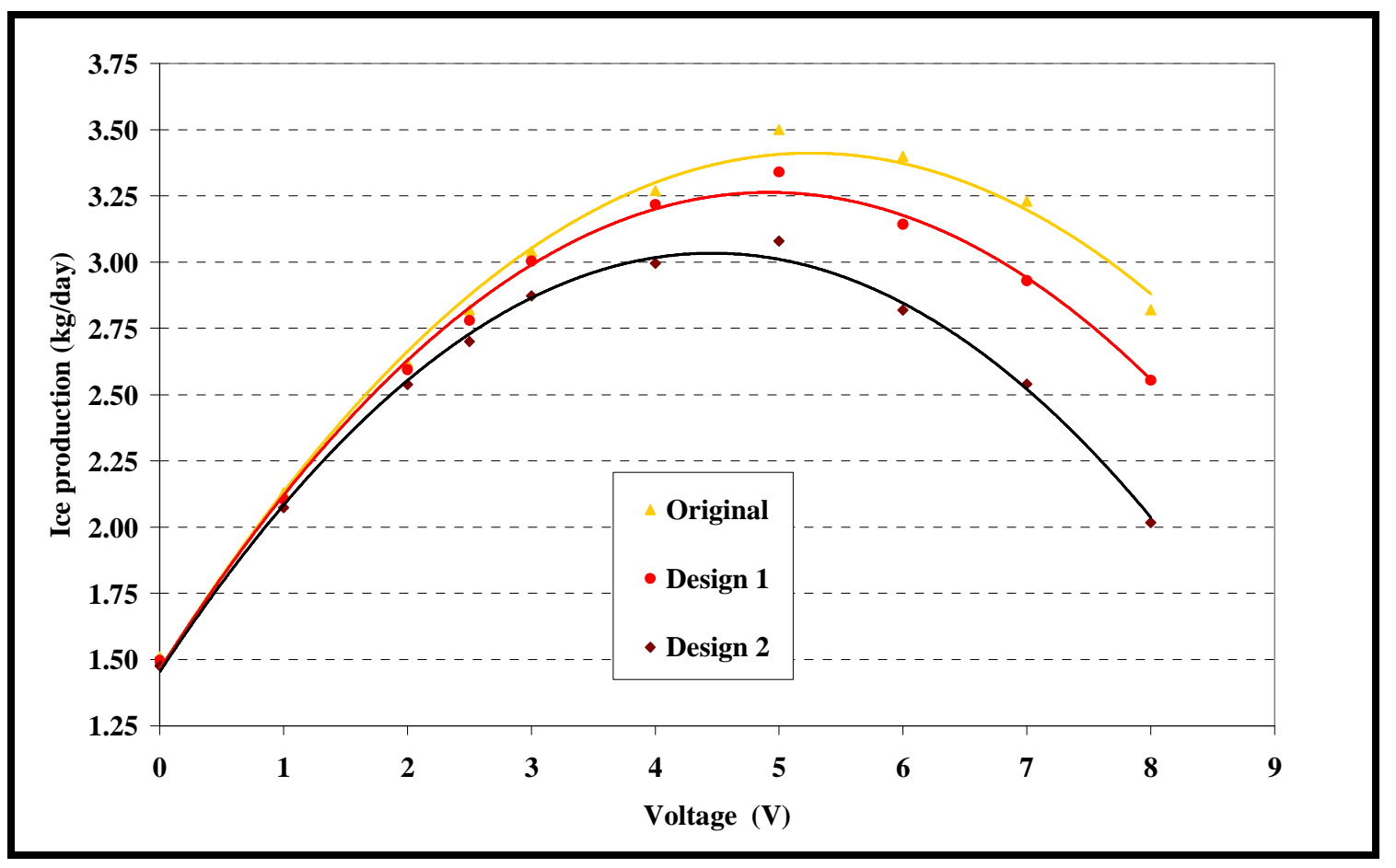

Fig. 5 Influence of the dissipator on the ice production (parallel fingers)

In the second place, Figure 6 shows a similar study to that presented in Figure 5, but including modified fingers instead of parallel ones. For $2.5 \mathrm{~V}$ of supplied voltage, design 3 reduces the ice production by $5.3 \%$ with respect to the original design, whereas designs 4 and 5 achieve reductions by 6.7 and $9.5 \%$ respectively. Although being the most disadvantageous case, design 5 still provides $2.55 \mathrm{~kg} /$ day of ice, which is considered to be acceptable. Moreover, material savings yield $65 \%$. 


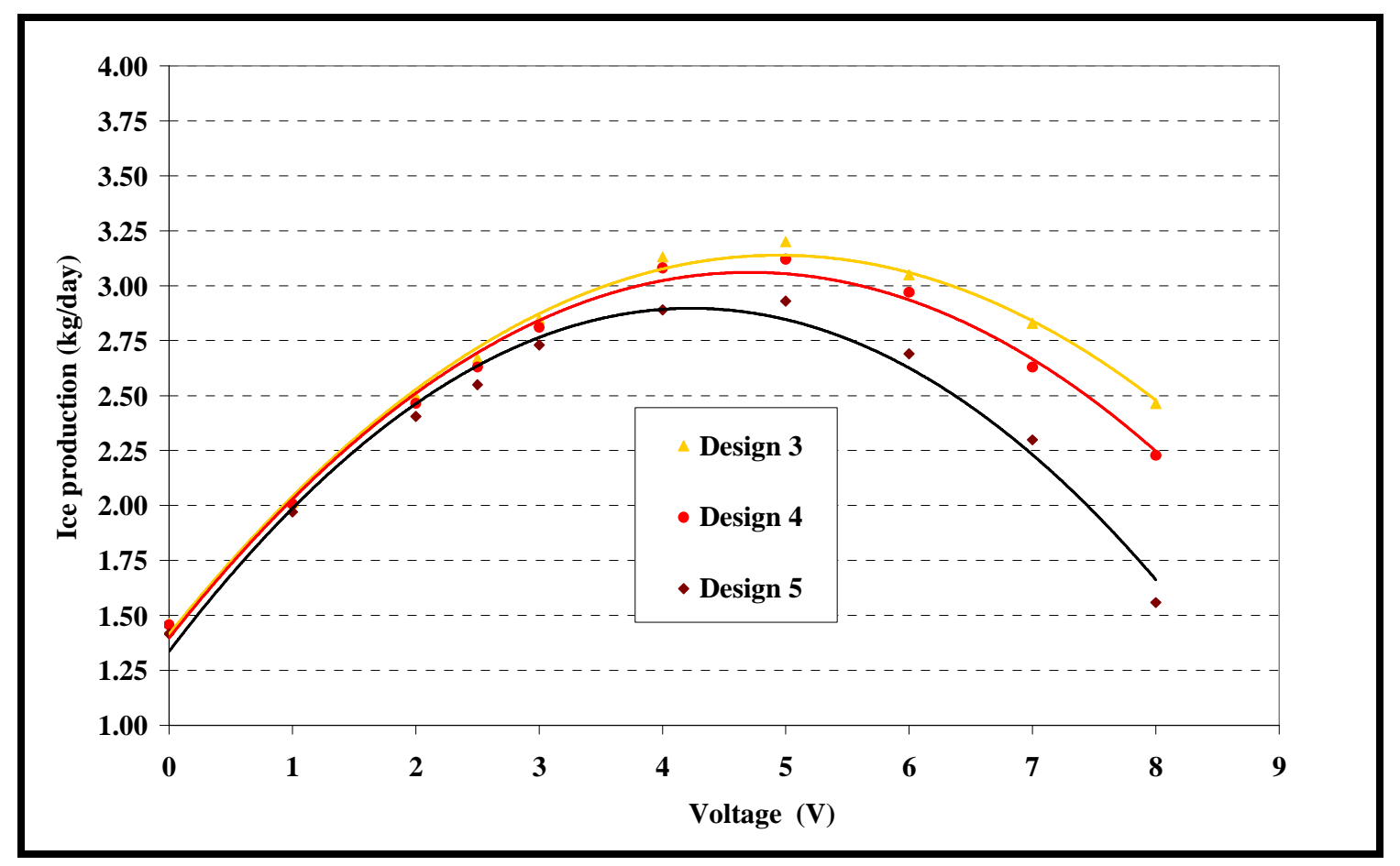

Fig. 6 Influence of the dissipator on the ice production (modified fingers)

Finally, designs 6 and 7 include one single thermoelectric module, so the thermal resistances of both dissipator and fingers increase, as was explained earlier. Figure 7 assesses the influence of the fingers on the performance of the thermoelectric ice maker. Then, for $2.5 \mathrm{~V}$ of supplied voltage, one can see that design 6 leads to an ice production of $2.33 \mathrm{~kg} /$ day, which means a reduction by $17.3 \%$ with respect to the original design. Likewise, the ice production achieved with design 7 yields $2.42 \mathrm{~kg} / \mathrm{day}$, which represents a reduction by $14.1 \%$. Moreover, design 7 reduces raw material by $65 \%$ and includes one single thermoelectric module, which allows saving half of the expenses assigned to the modules. 


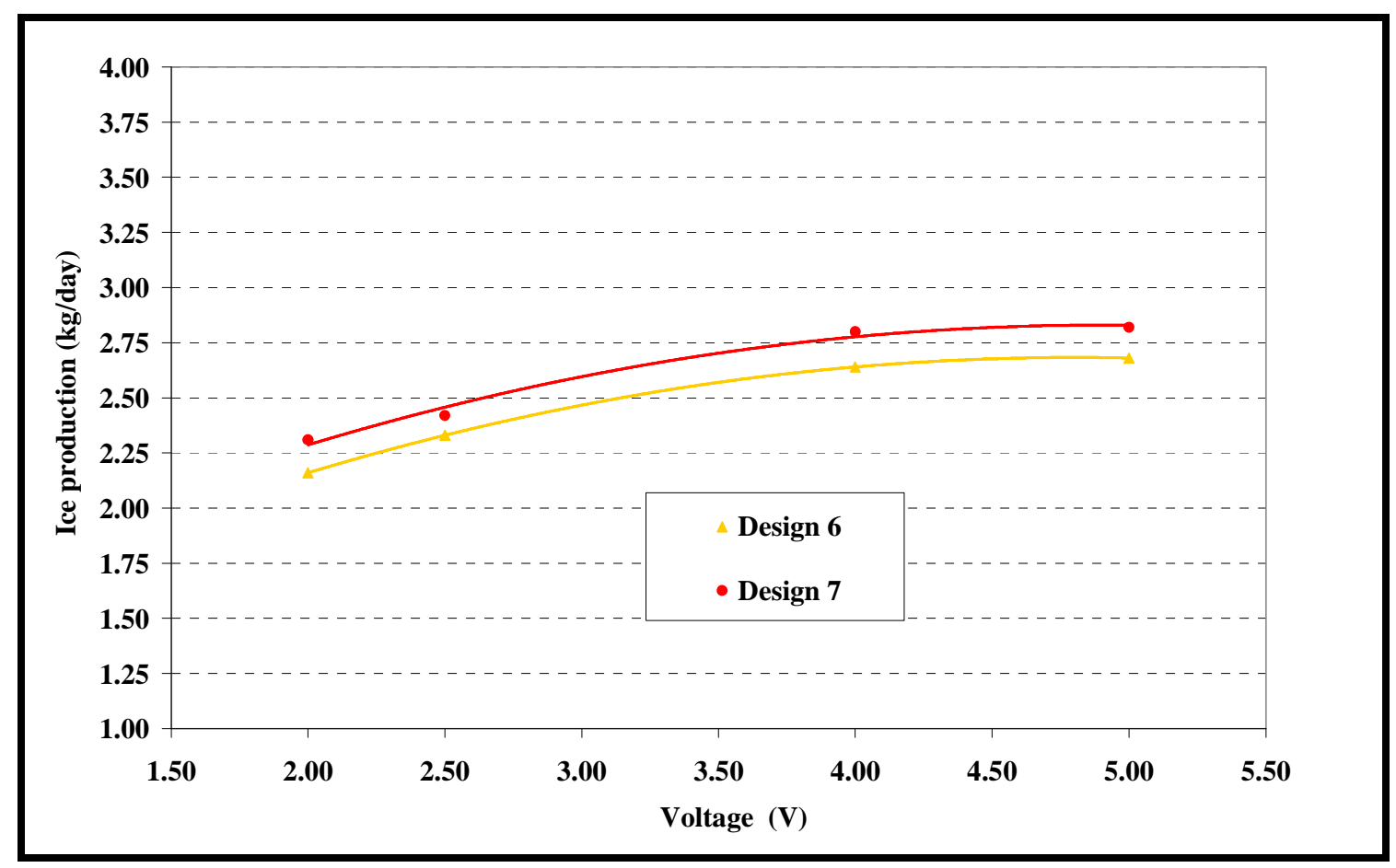

Fig. 7 Influence of the fingers on the ice production (one single thermoelectric module)

\section{Conclusions}

First of all, we established a methodology to find the upper limit of the voltage supplied to the thermoelectric ice maker that does not affect the normal performance of the refrigerator. Then, three dissipators with different space between fins were simulated and studied to assess their influence on the ice production. Finally, it was proved that the dissipator with $5.5 \mathrm{~mm}$ between fins leads to a maximum ice production of $2.82 \mathrm{~kg} /$ day with less than $7 \mathrm{~W}$ of extra electric power consumption, and it does not significantly affect the normal performance of the refrigerator.

Secondly, new designs of dissipator and fingers were proposed. MSCT assessed the influence of these designs on the ice production, and indicated that $2.55 \mathrm{~kg} / \mathrm{day}$ of ice can be produced with an ice maker that includes two thermoelectric modules and reduces by $65 \%$ the raw material. Moreover, the last design included one single thermoelectric module, and MSCT indicated that the ice production yields $2.42 \mathrm{~kg} / \mathrm{day}$, which is still acceptable, and reduces to the half the expenses assigned to the modules.

\section{References}

[1] G. Min, D. M. Rowe, Appl. Energ 83, 133 (2006)

[2] J. G. Vián, D. Astrain, M. Dominguez, Appl. Therm. Eng. 22, 407 (2002) 
[3] J. G. Vián, D. Astrain. Appl. Therm. Eng. 29, 1935 (2009)

[4] D. Astrain, J. G. Vián, J. Albizua, Appl. Therm. Eng. 25, 3149 (2005)

[5] A. Rodríguez, J. G. Vián, D. Astrain, Appl. Therm. Eng. 29, 2961 (2009)

[6] J. G. Vián, D. Astrain, A. Rodríguez, A. Martínez, J. Electron. Mater. 39, 1786 (2010)

[7] J. G. Vian, D. Astrain, J. Enhanc. Heat Transf. 12, 159 (2005)

[8] D. Astrain, J. G. Vian, M. Dominguez, Appl. Therm. Eng. 23, 2183 (2003)

[9] J. G. Vian, D. Astrain, Appl. Therm. Eng. 28, 1514 (2008)

[10] S. B. Riffat, S. A. Omer, Renew. Energ. 23, 313 (2001)

[11] B. J. Huang, C. J. Chin, C. L Duang, Int. J. Refrig. 23, 208 (2000)

[12] R. Chein, G. Huang, Appl. Therm. Eng. 24, 2207 (2004)

[13] R. Chein, C. Yehong, Int. J. Refrig. 28, 828 (2005)

[14] D. Astrain, J. G. Vián, A. Martínez, A. Rodríguez, Energy 35, 602 (2010)

[15] A. Martínez, J. G. Vián, D. Astrain, A. Rodríguez, J. Electron. Mater. 39, 1463 (2010)

[16] W. M. Rohsenow, J. P. Hartnett, Y. I. Cho, Handbook of Heat Transfer, 3rd edn. (McGraw-Hill, New York, 1998), pp. 334-351

[17] M. M. Yovanovich, Y. S. Muzychka, J. R. Culham, J. Thermophys. Heat Tr. 13, 495 (1999)

\section{Figure Captions}

Fig. 1 Sketch of the thermoelectric ice maker and the refrigerator

Fig. 2 Ice production and electric power consumption of the thermoelectric ice maker

Fig. 3 Sketch of the parallel fingers

Fig. 4 Sketch of the modified fingers

Fig. 5 Influence of the dissipator on the ice production (parallel fingers)

Fig. 6 Influence of the dissipator on the ice production (modified fingers)

Fig. 7 Influence of the fingers on the ice production (one single thermoelectric module)

\section{Table Captions}

Table 1 Influence of the space between the fins of the dissipator

Table 2 Thermal resistances of the fingers

Table 3 Thermal resistances of the dissipators

Table 4 Designs proposed and studied 